\title{
AS BIENAIS NACIONAIS 1970-76
}

Renata Cristina de Oliveira Maia Zago ${ }^{1}$

\section{Resumo}

No início de setembro de 2005 iniciei a organização da documentação histórica das Bienais de São Paulo realizadas nos anos 1970, em especial da XI Bienal Internacional de São Paulo (1971) no Arquivo Histórico Wanda Svevo da Fundação Bienal de São Paulo.

Para realizar este trabalho de maneira consistente e consciente foi preciso levantar além do material relativo a XI Bienal - catálogos da própria exposição, dados disponíveis no banco de dados daquela Fundação -, catálogos de outros eventos, como as Bienais Nacionais, a I Bienal Internacional do Livro (1970) e os Anais do Simpósio de Ciências e Humanismo (realizado em 1969, mas com a publicação datada de 1971); bem como realizar uma recorrente pesquisa ao Dossiê Ciccillo Matarazzo (fundo histórico em que se encontram documentos, fotografias e objetos pessoais do fundador da Bienal e do Museu de Arte Moderna de São Paulo), e ao acervo de livros e catálogos da Fundação Bienal.

Após a etapa inicial do trabalho, ou seja, a higienização, a primeira leitura e identificação dos documentos, constatou-se que uma parte das informações pertencia à I Bienal Nacional, chamada Pré-Bienal 1970. Verificou-se então, que a função da mostra foi selecionar a representação brasileira da XI Bienal Internacional de São Paulo.

Esse fato despertou meu interesse quanto ao caráter e a relevância destas mostras e sua projeção em âmbito nacional. Assim, além de iniciar a organização da documentação histórica pertencente a este certame (XI Bienal), iniciei uma pesquisa sobre as bienais nacionais.

\section{Antecedentes}

As Bienais Nacionais ocorreram durante o regime da ditadura militar brasileira. Neste período, diversos setores de atividade cultural e intelectual tiveram suas programações controladas.

A música, o teatro e o cinema foram atividades mais atingidas pela censura militar. No caso das artes plásticas, com um público mais restrito, houve o fechamento arbitrário de duas exposições: a II Bienal Nacional de Artes Plásticas, realizada em Salvador em 1968, e a mostra dos artistas brasileiros que representariam o Brasil na Bienal de Paris, no Museu de Arte Moderna do Rio de Janeiro, em 1969.

Estes fatos trouxeram como conseqüência o boicote à Bienal Internacional de São Paulo, em 1969. Segundo a historiadora e crítica de arte Aracy Amaral,

\begin{abstract}
as razões para o boicote têm sua origem em violentos atos de censura, praticados desde a II Bienal da Bahia (dezembro de 1968), contra seus organizadores, incluindo a remoção de obras de arte da mostra e de exposições em Belo Horizonte e Ouro Preto. A atitude mais chocante foi o encerramento, pelo governo, da exposição dos artistas brasileiros selecionados para a Biennale des Jeunes (a ser levada a efeito em Paris), que se realizava no MAM no Rio, devido a certas obras de arte que comportavam o protesto, ou eram de natureza erótica (AMARAL, 1983, 155).
\end{abstract}

\footnotetext{
${ }^{1}$ Mestranda do Instituto de Artes - Unicamp, renatazago@iar.unicamp.br
} 
Houve uma ausência marcante da comunidade artística de vários países. A representação brasileira foi, naturalmente, a mais prejudicada. Cerca de $80 \%$ dos artistas brasileiros convidados não compareceram, a exemplo de Carlos Vergara, Burle Marx, Rubens Gerchman, Sérgio de Camargo e Hélio Oiticica, entre outros. Na França, o crítico de arte Pierre Restany organizou um manifesto "Non à Biennale", de que, além deste país, participaram Estados Unidos, Bélgica, México, Holanda, Suécia, Argentina e Itália.

Dessa maneira, a Bienal contrariou seu principal propósito: atualizar o público brasileiro acerca das manifestações artísticas contemporâneas.

(...) distanciou-se quase por completo das tendências mais radicais, como a arte conceitual, a body art, arte povera, etc., que dominavam a cena artística naquele final de década. (...) o ramal mais produtivo da arte de então baseava-se na capacidade de buscar saídas alternativas ao circuito artístico, o que se fazia negando a noção mesmo de obra de arte em favor de seu conceito e ou da utilização de suportes precários ou efêmeros (FARIAS, 2001,148).

De acordo com notas divulgadas na imprensa da época (1970), havia uma promessa de renovação na estrutura da Bienal de São Paulo. E, analisando a documentação gerada pela X Bienal, pode-se perceber que a alternativa encontrada por Francisco Matarazzo Sobrinho e seus agentes culturais foi a criação da Pré Bienal de 1970 ou I Bienal Nacional de São Paulo.

\section{Pré Bienal 1970}

Este certame, como mencionado anteriormente, visava a construir um critério para a escolha da representação nacional na XI Bienal de São Paulo (1971).

O regulamento da Pré-Bienal foi organizado pela Assessoria de Artes Visuais da Fundação Bienal de São Paulo, integrada pelos críticos de arte Geraldo Ferraz, Antônio Bento e Sérgio Ferro.

O catálogo foi elaborado estabelecendo-se o critério de divisão dos artistas pelas áreas de seleção: Norte-Nordeste (englobando todos os Estados no Norte e Nordeste); CentroOeste (reunindo as seleções em Minas Gerais, Goiás, Brasília e Mato Grosso); Centro-Sul (obras que passaram por júris organizados no Rio de janeiro e em São Paulo) e, finalmente, Sul (Rio Grande do Sul, Santa Catarina e Paraná).

De acordo com a documentação gerada pelo evento, a Fundação Bienal efetuou cinco mostras prévias regionais nas cidades: Belo Horizonte, Recife, Brasília, Goiânia e Belém do Pará. $^{2}$

Dessa maneira, segundo Ciccillo Matarazzo, então presidente da Fundação Bienal,

O panorama buscado através de todo o imenso território nacional está aqui, naturalmente oferecendo deficiências e falhas que foram principalmente nossas - pois não pudemos bater de porta em porta e levar nossa convocação a todos os recantos. Nem ainda mais debater razões de ausência ou de indiferença à iniciativa, que por siso nos afigurava bastante a despertar o interesse e a participação (MATARAZZO, 1970, $9)$.

As fichas de inscrição, indicando o local de nascimento dos artistas participantes, apresentaram um resultado interessante: existem artistas de todos os Estados do Brasil, menos

2 Ofício PRÉ/2736, 30 set. 1970, localizado no Arquivo Histórico Wanda Svevo. 
Piauí e Maranhão, além de estrangeiros naturalizados ou radicados no país, que figuram entre os 258 selecionados em todo o Brasil.

Porém, isso não significa que os artistas participantes desta mostra e conseqüentemente os artistas selecionados para a XI Bienal representassem a arte de "vanguarda" da época. Percebemos com clareza esse fato, ao contrastarmos a Pré-Bienal ou a própria Bienal com eventos que ocorriam nos mesmos anos, como por exemplo, a Jovem Arte Contemporânea realizada no Museu de Arte Contemporânea da USP.

Permito-me aqui, a abrir um parêntese acerca da comparação acima citada. Conforme a historiadora da arte Dayse Peccinini,

as JACs (...) destoavam de tudo o que se via noutros locais da cidade. Muitos dos participantes jovens traduziam o inconformismo daquela interminável crise sóciopolítico-cultural. Fazia-se uma arte de crise. Eram happenings, mostras e espaços de material lumpen, debates (PECCININI, 1985, 124).

Estas mostras, denominadas JAC (Jovem Arte Contemporânea), foram eventos anuais, iniciados em 1967, que se repetiram por oito vezes consecutivas, consagrando-se como um dos espaços privilegiados da arte experimental no Brasil. Seu propósito era o incentivo da produção artística de jovens que se propunham ao trabalho não convencional de pesquisas de materiais e formas de vanguarda e à divulgação desta produção. A postura intelectualmente aberta de Walter Zanini permitiu aos artistas um diálogo livre, o que contribuiu para o prestígio da programação entre os jovens. Segundo Cristina Freire "o 'MAC do Zanini' não era apenas um lugar, mas, principalmente, um tempo" (FREIRE, 1999, 24). Naqueles anos, o lugar privilegiado do MAC-USP na cena artística paulistana era inquestionável. Lembramos que naquele momento o MAC-USP se configurava como um dos poucos locais onde os experimentos envolvendo, não raro, as imposturas em relação à noção instituída de arte eram aceitos.

Ademais, nos anos 1970 a interdisciplinaridade se firma através da apresentação de objetos, instalações, conferências e mesas de debates. Internacionalmente, bem como no Brasil, a arte se desenvolve em direção à valorização do processo, da idéia, dos multimeios. São utilizados os mais variados meios e técnicas. Cristina Freire afirma que

\footnotetext{
a tão debatida efemeridade das propostas lança a noção de arte como processo decorrente de uma idéia, de um objeto impalpável para o centro do debate. O esforço do artista, nesse período, vai no sentido de dar corpo ao invisível, tornar material uma idéia que não teria, necessariamente, apelos formais (FREIRE, 1999, 24-25).
}

E as obras apresentadas nas JACs dos anos 1970 tinham esse caráter. O MAC-USP tornou-se, sobretudo, identificado pelo estilo irreverente, agressivo e, muitas vezes, aberto a todas as experiências. De acordo com Zanini não se sabia quase sempre no que resultariam as mostras e os eventos da "geração 70", com tanta repressão em volta.

Diferentemente das experimentações realizadas nas JACs, as obras expostas nas Bienais Nacionais apresentavam, na sua maioria, suportes e propostas tradicionais.

\section{As outras edições das Bienais Nacionais}


As três edições seguintes das Bienais Nacionais apresentam a mesma finalidade da primeira: selecionar a representação nacional da próxima Bienal Internacional de São Paulo.

Porém, a segunda edição, chamada Brasil Plástica-72, além dos artistas escolhidos por região, trouxe uma inovação: uma Sala Especial de arte conceitual, arte e tecnologia, arte ambiental, proposições e pesquisas diversas, formada por artistas convidados, atentando talvez para os acontecimentos mais recentes do contexto artístico atual.

A terceira edição, Bienal Nacional-74, seguiu os mesmos parâmetros da primeira, porém, a Fundação Bienal, realizou paralela ao certame de 1974 uma Mostra de Gravura Brasileira, dos primórdios da gravura à atualidade.

Novamente podemos abrir uma discussão tendo em vista os acontecimentos artísticos da época. Ocorreram dois eventos importantes privilegiando as artes gráficas. No mesmo ano de 1974, no Museu de Arte Moderna de São Paulo houve o sexto Panorama, destacando o desenho e a gravura. E na cidade de Campinas houve o IX Salão de Arte Contemporânea de Campinas: Desenho Brasileiro 74. Esta mostra foi exposta no MAM - Rio de Janeiro em janeiro de 1975 e em março do mesmo ano em Brasília, na Sala de Exposições do Setor de Difusão Cultural.

A última edição da Bienal Nacional, em 1976, daria lugar, em 1978, a I Bienal LatinoAmericana, que ocorreu de fato, mas foi uma única edição.

\section{Referências Bibliográficas:}

AMARAL, Aracy (org.), Arte e meio artístico: entre a feijoada e o x-burguer. São Paulo: Nobel, 1982.

Catálogo Pré-Bienal de São Paulo, São Paulo: Fundação Bienal de São Paulo,1970.

Catálogo Bienal Nacional de São Paulo, São Paulo: Fundação Bienal de São Paulo,1972.

Catálogo Bienal Nacional de São Paulo, São Paulo: Fundação Bienal de São Paulo,1974.

Catálogo Bienal Nacional de São Paulo, São Paulo: Fundação Bienal de São Paulo,1976.

Catálogo Bienal Latino-Americana de São Paulo, São Paulo: Fundação Bienal de São Paulo,1978.

FREIRE, Cristina, Poéticas do Processo: Arte Conceitual no Museu. São Paulo: Iluminuras, 1999.

JAREMTCHUK, Dária, A Jovem Arte Contemporânea do MAC da USP, dissertação de mestrado, São Paulo: ECA-USP, 1999.

PECCININI, Daisy Valle Machado, Arte novos meios/multimeios: Brasil 70/80. São Paulo: Fundação Armando Álvares Penteado, 1985.

, Novas Figurações. Brasil anos 60. São Paulo: Itaú Cultural e Edusp, 1999.

ZANINI, Walter, $8^{\mathbf{a}}$ JAC - Jovem Arte Contemporânea, São Paulo: MAC-USP, 5/22 dez. 1974 (catálogo de exposição). 


\section{Figuras:}

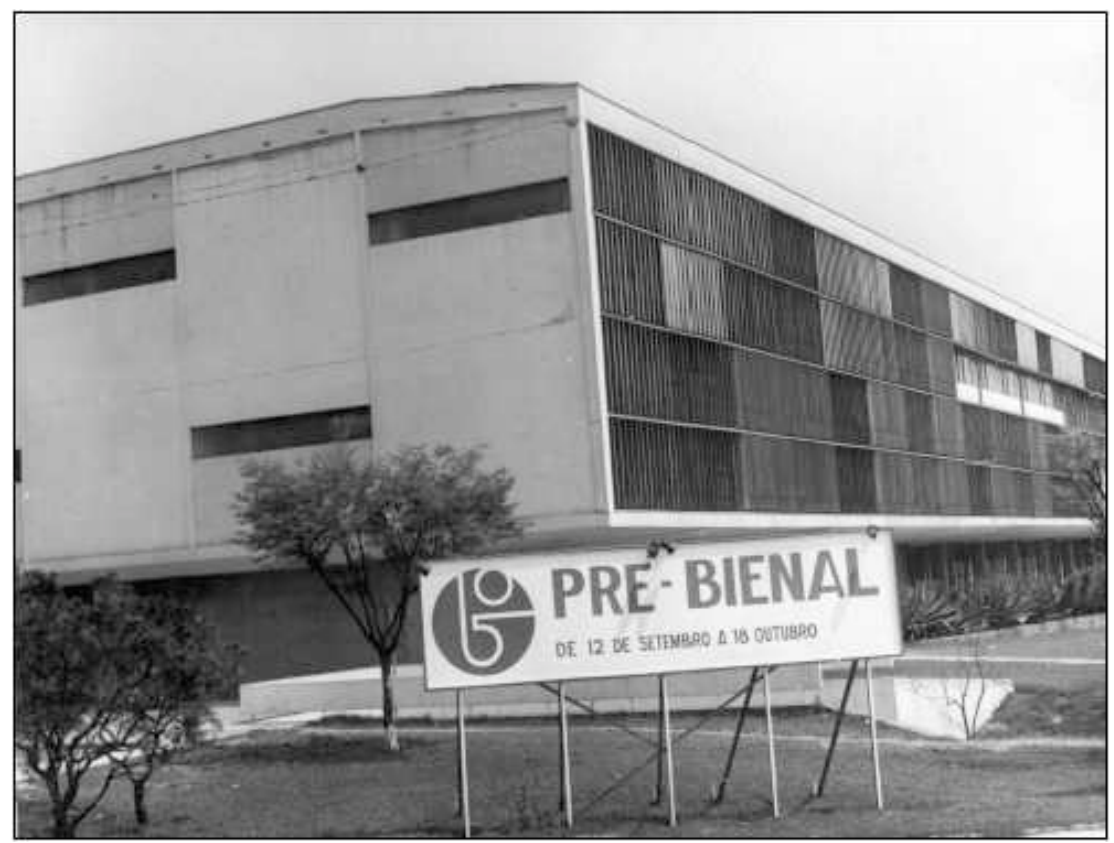

Pavilhão Ciccillo Matarazzo, Pré-Bienal 1970, Cortesia do Arquivo Histórico Wanda Svevo, Fundação Bienal de São Paulo

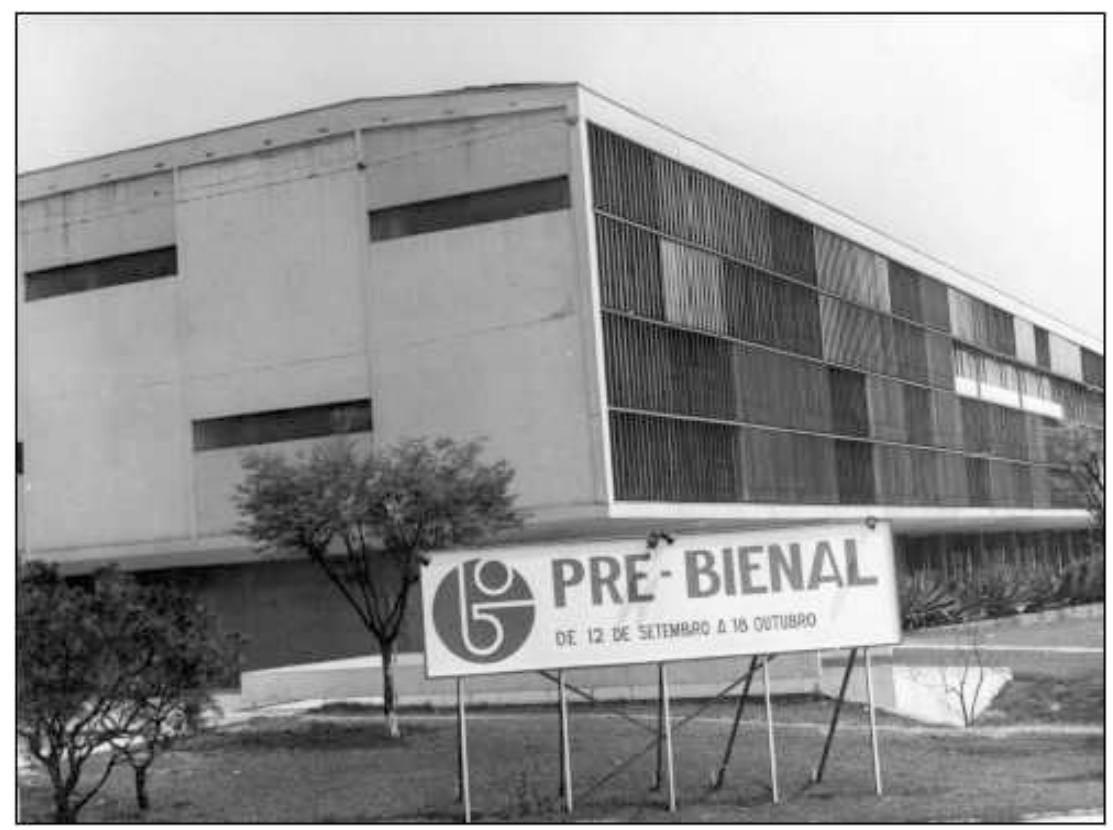

Entrada da III Bienal Nacional (1974) - Pavilhão Ciccillo Matarazzo, Cortesia do Arquivo Histórico Wanda Svevo, Fundação Bienal de São Paulo 